\title{
Undergraduate Student Teachers' Reflections on Their Teaching Practice Experience: Challenges Encountered and Responsive Solutions Employed
}

\author{
Wonderful Dzimiri* \\ Department of Educational Policy Studies and Leadership, Midlands State University \\ Pvt Bag 9055, Gweru, Zimbabwe \\ Samuel S. Mashingaidze \\ Department of Applied Education, Midlands State University \\ Pvt Bag 9055, Gweru, Zimbabwe
}

\begin{abstract}
The study investigated undergraduate student teachers' reflections on their teaching practice with a focus on challenges they experienced and how they reflectively responded or acted. Informed by both Experiential theory and Capital theory, the interpretive study employed a qualitative case study design. Twenty Bachelor of Education returning from their third year of teaching practice were purposively selected to represent school contexts typifying varied school contexts in Zimbabwe. Upholding ethical considerations, data were generated through interviews and focus group discussion. Thematic data analysis was used to organise data around recurring themes and their patterning constituents. Findings indicated that participants experienced challenges in respect of management of large classes, provisioning inclusive education, student indiscipline, teacher-teacher tensions and sour relations, and financial hardships. Responsive action in mitigating challenges faced evidenced reflective, experiential learning. Arguably, teacher educators should tap on student teachers' experiences as capital input into programmes that prepare students for teaching practice.
\end{abstract}

Keywords: Teaching Practice, student teacher, experiences, challenges, reflection, responsiveness.

DOI: $10.7176 / \mathrm{JEP} / 10-17-08$

Publication date:June $30^{\text {th }} 2019$

\section{Introduction}

Teaching Practice (TP), is an indispensable component of teacher preparation programmes, making practical teaching an integral part of teacher preparation programmes (Marais \& Meier, 2008), just as it is at the one university studied. Paramount importance of TP lies in that it transitions one from being a trainee to professional practitioner (Wagenaar, 2005). TP provides the student teacher with opportunity to 'test the waters,' give it a go at putting into practice, in a real classroom or school, those theories and principles learnt in college. Arguably, student teachers get to practice designing curricula through interpreting syllabi and subsequently drawing up schemes of work therefrom, lesson planning and preparation of relevant media for use during lesson delivery, teaching skills and managing relations with learners, other teachers and staff, and even parents of children taught.

Teaching Practice (TP) for the Bachelor of Education Honours Degree students at Pakati (pseudonym) University occurs during the third year (Level 3) of study for a full year, which is two semesters (semester 3.1 and 3.2) at schools of their choice nationwide, and even beyond Zimbabwe's borders for extra territorial students if they so wish. School choice for TP is the student's choice normally based on considerations such as access to free accommodation and low living expenses. While on TP, student teachers are attached to a qualified teacher in their discipline of study who becomes the student's mentor with responsibility to induct the student into the culture of the school and department of placement. The mentor also assists the student on the professional matters such as the culture of teaching and documentation, among many other responsibilities.

In this study, we investigated student teachers' reflections on their TP experience with particular focus on the challenges they faced and how they went about mitigating these challenges. Motivation to conduct this study arose out of our experience and conversations as coordinators of TP for both undergraduate and post graduate student teachers. Importantly, we felt the desire and need to enrich and inform our preparation of students for teaching practice in a broader manner, akin to bell hook's (1994) critical pedagogy that characterises 'teaching to transgress' - a preparation of student teachers that goes beyond in-class experiences and dynamics that one can bring to bear in the confines of micro-teaching. We felt also the desire and need to learn more about challenges that student teachers faced during TP and how they addressed the same, thus giving student teachers 'voice' in articulation of, and how they went about solving the challenges they faced. As researchers, we thus positioned ourselves as leaners from their own experience, viewed from the perspective of student teachers. At this point, it is important to share the lens through which we viewed and framed this study theoretically. 


\subsection{Theoretical and Literature Underpinnings}

Underpinning this study was, first, Experiential Learning Theory wherein experience, epistemologically, represents "learning and the process of gaining new knowledge" (Miettnen, 2000:54), which entails "experience, perception, cognition and behaviour" (p. 55). Solutions, (action) employed are a result of reflection (thought) on challenges experienced. That reflection on experience, rooted in critical theory, is central to development or growth of the actor who, in this case, is the student teacher.

Second, we also framed this study around Capital theory wherein intellectual capital concerns knowledge and skills, and experiences of people working together, as in a school, which transform into organised knowledge with spill-over benefits utilised in knowledge wealth production (Cadwell and Spinks, 2008). Generally, experiential learning is central in TP (Harrison, Dymoke \& Pell, 2006), if we are to take Dewey's theory of experience.

At the heart of the above framework lies also the importance of this study whereby the student teachers' and researchers' experience (out of social capital), in terms of challenges that student teachers faced and solutions they employed, becomes a source of intellectual capital that can be brought into reflection to inform future efforts towards programmes aimed at preparing student teachers for TP. Thus this study adds to the body of existing literature by bringing in experiences that are Zimbabwe-specific, and also specific to university-run teacher education programmes.

Sabar (2004) views a novice teacher deployed to a school from college as a stranger seeking to be accepted and tolerated by, and to belong to, the school as a social grouping. Student teachers are marginal to the school by their very status and dependence on school members to whom they wish to belong, and thus experience high stress characteristic of new entrance to a social situation (Breznits, 1979 in Sabar, 2004). As such, a student teacher new to a school is prone to experience and has to deal with in-class, in-school, as well as out-of-class and out-of-school challenges or problems that they encounter. However, student teachers' experiences of TP have 'highs' and lows,' or 'practice shocks' that characterise the very complex, and at times, emotionally challenging, TP experience (Meijer et al., 2011). A study by Msangya, Mkoma and Yihuan (2016) found inadequate supervision, lack of financial and material support, and negative attitudes of local school teachers as major challenges that student teachers in Tanzania experienced during their teaching practice. However, Mangya's et al. (2016) study did not seek how student teachers responded to the challenges they experienced given that responsiveness, as Kgomotlokoa and Nkadimene (2017) hold, is part of experiential learning resulting from reflection. Meijer's et al. (2011) study at a teachers' college in the Netherlands reported both negative (challenging), and positive experiences of student teachers. Among the negative experiences of student teachers were issues of classroom management and the 'practice shock' of learners not paying attention, misbehaviour in class, et cetera, leading to the student teacher's feelings of uselessness and shock. However, the study did not explore student teachers' consequent reflective action. Similarly, Kgomotlokoa and Nkadimene's (2017 study found classroom management as a challenge for the student teacher, but also that teaching practice offered opportunity for the student teacher to experiment and try out ways to address or solve challenges met relating to classroom competences, knowledge of learner deviant behaviour and conduct.

Research also acknowledges that a good relationship between the mentor teacher and the student teacher is indispensable (Ralph, 2000). The mentor teacher assists the student teacher with technical aspects of teaching as well as ensuring the conducive relationships and environment for the student teacher. Arguably, the mentor or supervisor teacher exerts tremendous influence on the development of the student teacher's orientation, disposition, conceptions and classroom practice (Farrell et al., 2000). As Marais and Meier (2004) allege, it also happens that the teacher mentor can exploit and abuse the student teacher by placing on him/her insurmountable demands and workload. At times, school teachers can also make the student teacher feel inferior and powerless in various ways. However, important in our study also was how student teachers reacted or responded to challenges as a consequence of reflecting on their experiences. As student teachers reflect on the TP experiences, they actively construct their own professional knowledge and understanding (Putman \& Barko, 1979 in Corney, 2006).

\subsection{The Problem}

Preparation of student teachers for Teaching Practice by academics has concentrated much on theory in a decontextualized manner. Similarly, supervision and assessment by university lecturers has tended towards theory-informed prescriptive suggestions, thus overlooking contextual realities involving student teachers' experiences, reflections and responsiveness characterising experiential learning (Thaba-Nkadimene, 2017). While researchers have studied student teachers' experiences in terms of problems and proceeded to propose solutions as experts or scholars (Marais \& Meier, 2004; Msangya, Mkoma \& Yihuan, 2016; Thaba-Nkadimene, 2017), very few have viewed students as experiential learners who reflect on, and respond to challenges they experience, thus learning and building on their professional knowledge capital. Thus, our study sought to explore student teachers' reflections in terms of challenges they experienced and how they reflectively responded to, or 
solved, the same.

1.2.1 Guiding questions

Two guiding questions assisted in focussing this study, and these were:

2.1.1 What challenges do undergraduate student teachers on teaching practice experience?

2.1.2. How do undergraduate student teachers respond to, or solve challenges faced?

\section{Methodology}

Given that we sought to understand the "world of human experience" (Cohen et al., 2005, p.15), we chose the interpretive lens to undergird this study to learn of student teachers' experienced challenges and how they reflectively responded to them. Taking a qualitative research approach, we employed a case study strategy in keeping with Stake's (1995) ideal, the particular being Pakati (pseudonym) State University Bachelor of Education Honours Degree student teachers who had just completed their one-year (two-semester) TP and returning to University for their fourth and final year of study. The study commenced during the first week of their 4.1 semester - a time during which we assumed student teachers' memories of their TP were still fresh. Twenty participants were purposively selected to represent the varied school contexts that typify Zimbabwe's school education landscape. We observed strict ethical protocols to include informed consent, voluntary participation and the right to withdraw from the study at any point, confidentiality and anonymity. In this report, student teachers are identifiable by the code (T) plus a one or two-digit identifier, thus T16 for example. This was in an effort to protect participants' identities. We generated data through in-depth interviews, which we audio-taped and transcribed in keeping with Merriam's (2009) advice. We then took back the interview transcripts to participants for their comments and endorsement (member checking). Data analysis commenced with data generation in line with qualitative research approach. Data were colour coded and organised around recurring themes that emerged from the data, and their patterning constituents (Litchman, 2006). In this report we use verbatim excerpts, not only to illustrate these themes, but to also give 'voice' to participants as well as weave the data into a story that participant student teachers tell.

\section{Results and Discussion}

The themes that emerged were specific to the aspect or area of challenge that student teachers encountered, and how they reflectively responded to the challenge. From the in-depth interviews conducted, five themes emerged. We therefore present each theme or challenge area followed by the respective response or action taken to address the challenge, therein engaging literature to form an educative discourse.

\subsection{Class management challenge}

Interview data revealed challenges relating to classes that were too large to manage or control, and attendant overcrowded classrooms and heavy marking loads. Tr.1 explained, "I had four classes of sixty plus each ... learners took advantage of that. The result was overcrowded classrooms, unfinished written work, noise and late coming. Similarly, Tr.4 also indicated, "Class control was challenging with sixty-four learners in one room that should normally house half the number." Notably, the issue of large classes had implications on, or rather created, conditions that impacted negatively on effective teaching and learning. Illustratively, Tr.4 bemoaned, "There was no space to even move around ... it was difficult to even sit a university lecturer or supervisor to observe me teach." Furthermore, and showing a concerned facial expression, Tr.6 said, "It was difficult for me to move around checking individual progress on written work due to overcrowding ... no space as learners are tightly packed." Bemoaning classes that were too large to manage, Tr.8 further indicated, "Marking 160 exercise books was stressful for me. ... you see; you end up not being thorough."

In agreement with Meijer et al. (2011), evidence in this study revealed negative experiences or challenges with issues of classroom management. Participants' responses pointed to indicators of 'practice shocks' at the large class sizes - too large to manage, crowded rooms with neither space to even move around nor sit a lecturer to observe the student teacher teach.

4.1.1 Responsive action to classroom management

In light of the challenge relating to class management, of interest to the researchers was how student teachers responded or what they did to address the challenge. Responses taken to address the challenge included seeking help from the seniors, being well organised, putting groups to effective use, improving time management and being punctual for lessons. As participant Tr.4 indicated, "I regularly sought assistance from the senior teachers and the school head." For Tr.1, "Being punctual reduced noise ... I had to be well organised and make effective use of groups and group leaders ... I had to improve on time as well." The one thing that participants could not change was the size of the class - a situation that impeded professional principles such as attending to learners' individual needs in class. Tr.8 expressed thus, "There was little I could do with class size ... I tried to use group tasks, but meeting individual needs to assist each pupil was difficult ... so I did very little to assist the slow, needy individual learners." 
While Kgomotlokoa and Nkadimene's (2017) study found classroom management as a challenge for student teachers, they argued that teaching practice gave student teachers the opportunity to experiment and try out ideas at addressing or mitigating challenges encountered in respect of classroom management issues. In this study, participants' responses, as a consequence of reflection, included time management, punctuality, making use of groups, and seeking support from senior teachers although meeting individual needs of learners was not easy with very large classes.

\subsection{Inclusive education provision}

Data generated showed that student teachers faced challenges in providing for inclusive education during their $\mathrm{TP}$, largely emanating from handling large classes and lack of capacity to handle inclusive classes. As Tr.8 said, "You are faced with abnormally large classes with diverse special needs learners. This was a huge challenge ... having a visually challenged learner ... and no clue what do." Tr.8's experience points to one's lack of competence or capacity to handle a visually impaired learner in a regular class, a situation which can be a source of stress itself. As Tr.4 bemoaned, "I had no training ... handling mentally and physically challenged kids! Oh I was depressed really ... worse still with no specialist teacher at the school to assist me - eish!"

When asked whether slow learners were assisted with remediation as expected in the university TP Guide and assessment criteria form or rubric, Tr.4 pointed out, "Slow learners were many also, but I could not provide remedial work for all these ... classes were just too large. I assisted only two or three per topic. An interview with Tr.10 revealed a very important dynamic that lays a condition in provision of inclusive education in a regular class, which is the importance of 'knowing' each learner. Expressing the challenge met in inclusive education provision, Tr.10 indicated, "It was difficult for me to know the habits of each learner, each learner's character and needs ... my classes were rather too big for me to know each learner".

In the context of Zimbabwe's Ministry of Primary and Secondary Education's inclusive education policy that brought learners with special needs and disabilities into regular classes, participants met challenges in meeting diverse special needs of learners, largely indicating their lack of preparedness or capacity to handle special needs learners such as the visually, mentally, and hearing challenged learners. Furthermore, large class sizes made it difficult for them to know each learner and their respective needs. As Sabar (2004) observes from Breznits (1979), these challenges with provision of inclusive education are some of the in-class experiences or problems that student teachers are prone to encounter and deal with during teaching practice.

4.2.1 Dealing with challenges of providing inclusive education

While participants in the study experienced challenges constraining their provision of inclusive education in regular classes due to lack of capacity and large class sizes, of interest to this study also was how they responded reflectively to address the challenge. Tr.11 said, "I tried remedial work and this was beneficial to a very small number and extent. However, I kept encouraging learners and assuring them that they will manage-just to keep them focused and motivated." Notable in this responsive action was effort at trying to do the best one could in the circumstance of large class sizes, and the importance of keeping learners focused and motivated. However, for some participants, it was sheer lack of capacity or knowledge on how to handle different special learners' needs yet, effort was made at responding to the challenge. This is seen best in the interview with Tr.1 who indicated thus,

While I could adjust and vary my teaching methods, I could not meet some learners' special needs,

and this required special training or preparation. I was not prepared to handle these special needs. I was at a loss how I could help this partially blind learner even though I was so concerned and worried.

While Corney (2004) cites Putman and Barko's (1979) position that student teachers' reflection on their experience leads to active construction of their own professional knowledge and understanding, evidence in this study reveals that such reflection and/or active construction can only dependent on one's possession of foundational knowledge and capacity on which to base responsive action. In this case, without prior knowledge or preparation (capacity building) on providing inclusive education or handling of special needs learners, student teachers could provide only remedial work and encouragement to slow learners. Otherwise, student teachers had not been trained or prepared to help learners with disabilities such as visual impairment. Without having been prepared at college to handle visually and mentally challenged learners among others, meeting these - without expectation - must have been a source of 'practice shocks' (Meijer et al., 2011) for the unsuspecting student teacher.

\subsection{Student indiscipline}

A third recurring area of challenge that emerged from interview data related to participants' concern over student or learner indiscipline inside and outside the classroom. Cases ranged from mischief, disrespect, absenteeism from lessons, failure to write assigned work, to fights and other disruptive behaviours. According to Tr.1, "Most learners were mischievous, rude, disrespectful and arrogant." This was coupled with, "Low lesson attendance 
rate ... and learners did not write assignments ... did not do their corrections," said Tr.15. Linked to the class control challenge in the context of large class sizes reported above, Tr. 5 explained thus,

With a teacher pupil ration of 1:58, it was difficult to control the learners ... worse because I was given low performing classes whose participation in lessons was very low. Fights, shouting, namecalling plus other disruptive behaviours were common."

While evidence revealed learner indiscipline as a challenge in class, data indicated also that participants had challenges with student indiscipline outside of the classroom-based teaching and learning. As Tr.5 indicated, “Controlling learners' disruptive behaviour during outdoor activities was a big challenge." The context of outdoor activities or the types of activities is illuminated in an excerpt from an interview with Tr. 16 who specified thus, "Learner misbehaviour out of class during general work, sports, quiz, and drama competitions was a big challenge. We therefore see student teachers struggling with learner indiscipline or misbehaviour in and out of class contexts, a challenge that Kgomotlokoa and Nkadimene (2017) also found in their study. Similarly, we see evidence of what Meijer et al. (2011) termed 'practice shock' of learners not paying attention, misbehaviour in class, et cetera, all of which may result in feelings of uselessness and shock for the student teacher. Breznits (1979) had earlier observed, apart from in-class, the presence of in-school and out-of-school challenges for the student teacher new to a school. However, our interest as researchers lay also in how student teachers responded to such challenges as a result of reflection on such experiences.

4.3.1 Acting on student indiscipline

Evidence revealed how student teachers responded to student indiscipline in a number of ways. There was general agreement on engaging in child study in order to understand the learner. As T10 stated, "I learnt that sometimes to understand a learner you needed to know each child, his or her background in order to tackle indiscipline." Seemingly, student teachers acknowledged their loco parentis role.

A second recurring response pointed to utilisation of existing school level structures in dealing with continuous problem cases. T13's response summed up thus, "For problem children who gave me continuous discipline problems, referring them to the disciplinary committee, senior teacher, and/or the Deputy School Head really worked for me, and it helped because things changed with learners. Inviting parents to the school for a conference on their child's behaviour was another strategy reported to have worked. In the words of T11,

After trying to no avail, I realised the importance of enlisting parental involvement to assist in controlling the learners' misbehaviour and rude attitude towards superiors, at times after I tried and failed, and referred the learners to the senior master and later felt the senior masters' efforts did not change the learner. Involving parents in extreme cases actually helped me, and we kept talking with parents on the student's progress.

The above excerpt points to the importance of the "natural partnership that the school and home should play in the child's education. As T18 retorted, "With behaviour problem learners, you can't win if you don't involve the parents. Data evidenced the need for constant contact with the parents, and also acknowledging positive change in the learner. As T16 testified, "I increased the rate of communication with parents of concerned pupils. This home-school link ... with agreed disciplinary and monitoring measures, reduced cases of indiscipline in general. Participants also acknowledged their loco parentis role as teachers in terms of offering guidance and counselling. An excerpt from an interview with T15 illustrates thus,

I tried guidance and counselling, paid individual attention to problem learners. I monitored and made sure they did their work ... really, I had to play a co-parenting role-making sure each learner is in the right place, especially my problem learners.

Responses from participants revealed that student teachers evidenced experiential learning - a process of gaining knowledge resulting from thought processes (reflection) on challenges with learner indiscipline, which resulted in some 'action' or response (Miettnen, 2000) to address the challenge, that is, through utilisation of structures that existed in the schools to include referring problem learners to the school disciplinary committee, senior teacher, and/or deputy school head. Where in-school structures failed, student teachers enlisted partnership with the parent(s) wherein regular communication between the teacher and parent assisted in monitoring the learner's behaviour from both ends.

\subsection{Teacher-teacher tensions/sour relations}

Data generated also revealed that student teachers experienced challenges relating to teacher-teacher tensions and sour relations, resulting in the student teacher feeling uncomfortable, making team work unproductive, and thus creating a climate or atmosphere that defeated professional development. As T11 put it, "I felt very uncomfortable when I discovered that some senior teachers did not positively interact with each other." On another note, T10 alleged,

Tension between teachers made work so grim for me as student teacher. Such tensions and conflicts between teachers created an environment not conducive to professional development ... at times I was looked down upon, gossiped over as not able to teach, making it difficult for me to seek help where I 
needed it.

The excerpt above depicts a situation unfavourable to professional development of student teachers that accrues from interaction with teachers in post. T17 claimed that, "Some of the teachers were difficult to work with, and teamwork was not very productive." Evidence pointed also to experiences of tensions between student teachers and teachers in post that translated to harassment, specifically directed at some female student teachers. An excerpt from an interview with T12 clearly brought out the dynamics to the fore:

The worst challenge for me was that of being asked out by male teachers. About four male teachers asked me out - actually three were married, at times with threats of making my life a living hell at the school if I didn't give in to their demands.

Quite apparent in the expressions above is the fact that tensions and conflicts are inevitable in school settings, yet at the same time creating an organisational atmosphere that is counterproductive to professional development of the student teacher. Of particular concern were experiences tantamount to sexual harassment. As Breznits (1979) acknowledges, as new entrants to the school, the student teacher is rendered dependent on school members. Where the social situation becomes uncomfortable or threatening, the student teacher experiences high stress levels (in Sabar, 2004). How then did they respond after reflection?

4.4.1 Reflective action on teacher-teacher tensions/sour relations

Data showed that participants reflected on their experiences of tensions and conflicts among, between, or with teachers in post. Their reflective actions entailed respect, embracing difference, adapting to situations, keeping out of others' petty issues and keeping their distance. T8 said, I had to respect and accept difference, accept to be corrected when I'm wrong." Similarly, T17 indicated, "I learnt that as a teacher I had to respect fellow teachers for who they are." It was thus important for student teachers to embrace and appreciate difference, yet still being able to respect others. Data generated also revealed that, to be able to do so required flexibility and adaptation and 'minding one's own business.' As T10 expressed, "I had to adapt to the situation, being flexible and humble, and making sure not to entangle myself into other people's petty issues and differences." Being flexible and playing safe was a strategy adopted to survive in contexts of conflict and tensions among and between teachers.

Sexual harassment accompanied by threats was a challenge common to female student teachers who reflected on their experience, and yet responded to the challenge. T12, in response to harassment by male senior teachers, mostly married, utilised a formal structure of her mentor. She said,

I told my mentor who was a senior teacher and expressed my fears. The mentor spoke to all male teachers in the staffroom at break time to stop it. Thereafter, I received no threats ... but relations were not very smooth thereafter... I kept my distance of course.

The above excerpt from T12 reveals the importance of giving oneself 'voice' and use of formal structures in the school, yet such experiences can potentially make the student teacher feel powerless and inferior. As Ralph (2000) supported by Marais and Meier (2004) argues, the relationship between the mentor teacher and the student teacher is indispensable. Apart from assistance with technical aspects, the mentor teacher must ensure conducive relationships and environment for the student teacher. Arguably, female student teachers require protection and support to survive issues of taunting, abuse and harassment by male colleagues while on TP, and the mentor teacher naturally occupies the call-face position. As Ferrell et al. (2000) argue, the mentor teacher exerts tremendous influence on the student teacher's development, orientation, disposition, et cetera.

\subsection{Lack of financial support}

Participants in the study reported low motivation during their TP arising from absence of financial incentive for the two semester (one year) period of teaching practice. While they paid full fees to the university, lack of financial support was a source of demotivation generally. In recalling the challenge, T2 said, "At times I went without food supplies." Wearing a sad face, T10 recalled; "At times I went to work on an empty stomach without having eaten anything at all ... no money for food." While failure to have food supplies was a serious basic survival issue judging from Maslow's Hierarchy of Needs Theory, there was concern too over failure to purchase job essentials given the harsh economic situation in Zimbabwe at the time of this study.

Delivery of successful lessons requires resources that schools failed to provide, yet the student teacher needed these for effective teaching and learning. As T9 aptly stated, "A major challenge was lack of money to by stationery and materials for lessons." On a similar note, T9, with emotion and bitterness written in his eyes said, "... I was not paid for a whole year yet expected to wear formal attire, which is expensive, buy manila paper for charts and instructional media with my own money that I don't even have." T16 expressed the plight of the student teacher saying, "The reality was digging into one's empty pocket to buy teaching - learning resources ... that's tough I tell you." Arguably, the teaching profession laid certain expectations such as the dress code and basic teaching-learning media, which posed a challenge for the 'unpaid' student teacher on practice. It was evident from data that absence of financial incentive had negative implications for the student teacher. For the female student teacher, "Not being paid made life difficult for the student teacher on TP" (T18). As student 
teacher T6 summed up,

Absence of an allowance can easily send us ladies into unorthodox means of getting money if you are not of strong character. You see, we really don't want to have 'sugar daddies' or be a 'lady of the night' [prostitution] kkkkkkkk (laughter).

Much of literature available (Ralph, 2000; Farrell, et al., 2000; Marais \& Meier, 2004; Meijer et al., 2011) appears silent on issues of student welfare, Mangya et al. (2016) pinpoint lack of financial and material support as major challenges, among others. Equally important in our study was finding out how then student teachers responded to the above challenges.

4.5.1 Responses to financial hardships

Given that responsiveness is part of experiential learning as a consequence of reflection (Kgomotlokoa \& Nkandimene, 2011), data revealed that student teachers took action in response to financial hardships and material challenges. Basically, approaching senior personnel in the school and relatives for help, as well as being entrepreneurial assisted student teachers to cope with the financial challenge. T9 said, "I talked to the school head at one time and I was given sugar ... it's better than nothing." In other instances, reflecting on the challenge led to responses that were more productive as revealed in the excerpt from an interview with T18, who indicated thus, I sourced money from relatives, conducted extra lessons outside school environment with external students to get money, and I made use of other personal skills outside teaching to earn some money.

Evidence gathered indicated that student teachers made efforts towards easing their dire financial situation through entrepreneurial undertakings to raise money to purchase food and teaching and learning resources. The words by T9 illustrate thus,

I managed to strive through and hatched a plan to conduct extra [private] lessons at home [for a fee] with formal school learners. This made work easier and I managed to pay for lunches and also buy stationery and media that I needed for my lessons.

Participants could have utilised knowledge and insights gained from a module on entrepreneurship offered as part of their study programme, which is undertaken before students go on TP.

\section{Conclusion}

Findings in this study revealed student teachers' active construction of own professional knowledge and understanding wherein participants experimented and tried out ways to mitigate challenges they faced. Characterising their experiences were reflections on their situation and responsive actions geared at mitigating challenges faced. Adding to the list of 'practice shocks' in existing literature on student experiences, which training universities would otherwise rarely prepare student teachers on, are challenges relating to their welfare in practising schools, as well as financial advisement and how to cope.

\section{Recommendations}

It is often the case in most research reports that the researcher, basing on findings, offers recommendations, thus positioning oneself as an expert at solving problems or challenges experienced by the 'other'. In keeping with the critical, emancipatory perspective, and the attendant desire to give research participants 'voice', we further asked student teachers, as part of their reflective experiential learning, to provide advice or recommendations that could improve the student teachers' TP experience, thus mitigating challenges they experienced. We thus provide verbatim excerpts of student teachers' recommendations in the hope that teacher educators and directors/coordinators of Teaching Practice embrace these as capital input, or what Cadwell and Spinks (2008) refer to as knowledge wealth produced, which can be utilised for further improvement of student teachers' TP experience. The following were student teachers' (verbatim) recommendations:

6.1 "Ministry of Primary and Secondary Education must consider unfreezing posts and reduce class sizes down to like thirty-five";

6.2 "Schools should hold awareness campaigns with parents on student discipline;"

6.3 "Schools should work closely with parents - that communication link is vital";

6.4 "Schools should engage school leavers, who in most cases lure learners into drug abuse, drinking and smoking, through projects, sports, and even adult classes";

6.5 "Universities must prepare us for inclusive classes ... how to handle special needs learners ... you see, basic sign language for the deaf, braille for the visually impaired, and others. They are there in the ordinary [regular] class and we must teach them";

6.6 "Schools should work on conflict resolution ... maybe staff development and setting up structures for resolving conflict in schools. And University must also give us more knowledge on conflict management in preparation for our TP"; and

6.7 "If student teachers from teachers' colleges receive an allowance, we need it too for university students. Our university must engage government seriously and urgently, otherwise TP is a year of financial hell for us." 


\section{References}

bell hooks (1994). Teaching to transgress: Education as the practice of freedom. New York: Routledge.

Caldwell, B. J., \& Spinks, J. M. (2008). Raising the stakes: From improvement to transformation in the reform of schools. London: Routledge.

Cohen, L., Manion, L., \& Morrison, K. (2005). Research Methods in Education. (5 ${ }^{\text {th }}$ ed.) London: Routledge.

Corney, G. (2006). Education for Sustainable Development: An Empirical Study of the Tensions and Challenges Faced by Geography Student Teachers. International Research in Geographical and Environmental Education, 15 (3), 224-240.

Ferrell, M. A., Walker, S., Bower, A., \& Gahan, D. (2000). Researching Early Childhood Student Teachers; Life Histories and Course Experience. International Journal of Early Childhood, 32 (1), 34-40.

Harrison, J., Dymoke, S., \&Pell, T. (2006). Mentoring Beginning Teachers in Secondary schools: An Analysis of Practice. Teaching and Teacher Education, 22, 1055-1067.

Marais, P. \& Meier, C. (2004). Hear our Voices: Student Teachers' Experiences During Practical Teaching. Africa Education Review, 1 (2), 220-233.

Litchman, M. (2010) Qualitative research in education: A users' guide London: Falmer Press.

Meijer, P. C., de Graaf, G., \& Meirink, J. (2011). Key Experiences in Student Teachers' Development. Teachers and Teaching: Theory and Practice, 17 (1), 115-129.

Merriam, S.B. (2009). Qualitative research: A guide to design and implementation. San Francisco: Jossey-Bass.

Miettinen, R. J. (2000). The Concept of Experiential Learning and John Dewey's Theory of Reflective Thought and Action. International Journal of Lifelong Education, 19 (1). 54-72.

Msangya, B. W., Mkoma, S. L., \& Yihuan, W. (2016). Teaching practice Experience for Undergraduate Student Teachers: A Case Study of the Department of Education at Sekoine University of Agriculture, Tanzania. Journal of Education and Practice, 7 (14), 113-118.

Ralph, E, G. (2000). Aligning Mentorship style with the Beginning Teacher's Development: Contextual Supervision. The Alberta Journal of Educational research. XLVI (4), 211-326,

Sabar, N. (2004). From Heaven to Reality through Crises: Novice Teachers as Migrants. Teaching and Teacher Education. 20. 145-161.

Thaba-Nkadimene, K. L. (2017). University of Limpopo Student Teachers' Experiences and Reflections during Teaching Practicum: An Experiential Theory. International journal of Educational sciences, 17 (1-3), 205214.

Wagnaar, M. (2005). Student Teachers' Experiences of Practice Teaching. Unpublished Dissertation. UKZN. 